\title{
Relationship Between Polypharmacy and Quality of Life Among People in 24 Countries Living With HIV
}

\author{
Chinyere Okoli, MSc ${ }^{1}$; Patricia de los Rios, $\mathrm{MSc}^{2}$; Anton Eremin, $\mathrm{MD}^{3}$; Gary Brough, $\mathrm{BA}^{4}$; \\ Benjamin Young, MD, $\mathrm{PhD}^{2}$; Duncan Short, $\mathrm{PhD}^{1}$
}

\section{Accessible Version: www.cdc.gov/pcd/issues/2020/19_0359.htm \\ Suggested citation for this article: Okoli C, de los Rios P, Eremin A, Brough G, Young B, Short D. Relationship Between Polypharmacy and Quality of Life Among People in 24 Countries Living With HIV. Prev Chronic Dis 2020;17:190359. DOI: https:// doi.org/10.5888/pcd17.190359.}

\section{PEER REVIEWED}

\section{Summary}

What is already known on this topic?

People living with HIV (PLHIV) have greater incidence of comorbidities and higher prevalence of polypharmacy, most commonly defined as taking 5 or more medications concurrently, than the general population.

What is added by this study?

PLHIV reporting polypharmacy had significantly worse overall health outcomes, including significantly lower prevalence of self-reported virologic control and treatment satisfaction. These findings were significant despite controlling for presence of comorbidities.

What are the implications for public health practice?

By actively assessing patients holistically and considering how increased medication may influence individual behavior to health outcomes, clinicians may contribute to improving health-related quality of life among people living with HIV.

\section{Abstract}

\section{Introduction}

People living with HIV (PLHIV) have greater risk of having multiple health conditions. We measured the relationship between increased medication and overall quality of life among PLHIV from 24 countries.

\section{Methods}

We analyzed data for 2,112 adult PLHIV on antiretroviral therapy (ART) in 24 countries who completed the 2019 Positive Perspectives survey. Polypharmacy was defined as taking 5 or more pills a day or currently taking medications for 5 or more conditions. Outcomes were self-rated overall health, treatment satisfaction, and self-reported virologic control. New treatment concerns were issues not prioritized at ART initiation but now deemed paramount. Data were analyzed with descriptive and multivariable statistics.

\section{Results}

Overall prevalence of polypharmacy was $42.1 \%$. People reporting polypharmacy had significantly poorer health outcomes independent of existing comorbidities; their odds of treatment satisfaction, optimal overall health, and virologic control were lower by $27.0 \%$ (adjusted odds ratio $[\mathrm{AOR}]=0.73 ; 95 \% \mathrm{CI}, 0.59-0.91), 36.0 \%$ $(\mathrm{AOR}=0.64 ; 95 \% \mathrm{CI}, 0.53-0.78)$, and $46.0 \%(\mathrm{AOR}=0.54,95 \%$ CI, 0.42-0.70), respectively, compared with those without polypharmacy (all $P<.05$ ). Most PLHIV $(56.6 \%)$ were concerned about taking more medicines as they age, and $73.1 \%$ were interested in ARTs with fewer medicines. Top reasons for switching ART among those who had ever switched $(\mathrm{n}=1,550)$ were to reduce severity and frequency of side effects $(45.3 \%)$, number of pills $(35.0 \%)$, or number of medicines $(26.8 \%)$. People reporting polypharmacy had significantly higher odds of having new concerns relative to when they initiated ART, regarding risks of drug-drug interactions $(\mathrm{AOR}=1.32 ; 95 \% \mathrm{CI}, 1.02-1.71)$ and side effects $(\mathrm{AOR}=1.31 ; 95 \% \mathrm{CI}, 1.02-1.68)$.

\section{Conclusion}

Polypharmacy was associated with poorer health-related outcomes among PLHIV. Many PLHIV expressed concerns about side effects of ART. Clinicians should carefully consider patient preferences, comorbidities, and drug profiles when prescribing ART. 


\section{Introduction}

With advances in antiretroviral therapy (ART), the life expectancy of people living with HIV (PLHIV) has increased (1-4); nevertheless, they are at higher risk for multiple health disorders $(5,6)$. As with many other chronic illnesses, HIV management goes beyond drug treatment; holistic care is paramount. In its definition of health, the World Health Organization shifted its focus from diagnosis-focused approaches to ones that highlight the person's positive overall well-being and quality of life across physical, mental, and social domains (7). This paradigm has also emerged within the HIV community with the incorporation of the "fourth 90," calling for improvements in health-related quality of life. The fourth 90 evolved from the global 90-90-90 targets of the Joint United Nations Programme on HIV/AIDS, which called on health systems to increase diagnosis of HIV, treat a greater number of those diagnosed, and ensure that those being treated achieve viral suppression. (8).

Focusing entirely on a specific disease reduces the health care provider's ability to personalize care for a person affected by a host of comorbidities. Other than medical care, a person's health is significantly determined by environmental, sociopsychological, and economic factors (9). Hence, success measured purely by clinical outcomes may not mitigate disease. Delivery of fragmented care to patients affected by multiple conditions, even when based on strict adherence to disease-oriented treatment guidelines, promotes polypharmacy, which may increase likelihood of adverse or even antagonistic treatment effects (10).

Because PLHIV have more non-AIDS comorbidities, a comprehensive approach is needed to evaluate the relationship between increased medication and overall quality of life. Polypharmacy rates among PLHIV, which range from $23 \%$ to $39 \%$, are higher than among HIV-negative populations (11-15). Studies have demonstrated associations between polypharmacy and clinical outcomes, including death (16); however, data are scarce on the relationship between polypharmacy and overall quality of life based on subjective measures of well-being that are important to patients $(17,18)$, including their experiences, concerns, and treatment priorities. To fill these gaps in knowledge, we used pooled data from 24 countries to examine associations between polypharmacy and self-rated overall health and perceptions of treatment needs.

\section{Methods}

\section{Data source}

We conducted a cross-sectional study, Positive Perspectives, from April through August 2019 in 24 countries; 2,112 PLHIV aged 18 to 84 participated. Participating countries and the achieved sample size were United States $(n=400)$, United Kingdom $(n=123)$, Australia $(n=120)$, Canada $(n=120)$, France $(n=120)$, Germany $(\mathrm{n}=120)$, Italy $(\mathrm{n}=120)$, Spain $(\mathrm{n}=120)$, Japan $(\mathrm{n}=75)$, Mexico $(n=63)$, Portugal $(n=60)$, Brazil $(n=58)$, Russia $(n=57)$, Taiwan $(n=55)$, Netherlands $(n=51)$, Argentina $(n=50)$, Austria $(\mathrm{n}=50)$, Chile $(\mathrm{n}=50)$, China $(\mathrm{n}=50)$, Ireland $(\mathrm{n}=50)$, Belgium $(n=50)$, Poland $(n=50)$, South Korea $(n=50)$, and Switzerland $(n=50)$. To be eligible, respondents had to verify that they were HIV sero-positive and receiving treatment (eg, by presenting their ART prescription or a letter from their medical provider); those not currently on HIV treatment $(31.6 \%)$ were excluded. Financial incentives (approximately $£ 20$ GBP or the local equivalent) were provided to encourage participation. Participants were recruited by using targeted and snowball sampling approaches across multiple platforms and in collaboration with multiple HIV organizations; responses were collected over the web or in person. Adaptive sampling was performed to make the distributions of participants in each country more representative. This study was deemed exempt research by the Pearl Institutional Review Board (no. 18-080622).

\section{Measures}

Polypharmacy. Polypharmacy has no universal definition (19); however, one commonly used definition is 5 or more medications concurrently (20). We defined polypharmacy as taking 5 or more pills a day or taking medicines for 5 or more health conditions. This definition, which distinguishes pills (dosage form of a medicine) from medicines (the actual pharmacologic agent) is conservative inasmuch as a single pill could contain more than 1 medicine, which is likely with ART (21), and more than 1 medication could be used to treat a single condition. Survey participants were asked their frequency of taking HIV and non-HIV pills and were also shown a detailed list of health conditions to ascertain which ones they were currently taking medicines for. Polypharmacy was assessed independent of the presence of diagnosed comorbidities; for example, people taking 5 or more medications for 1 condition would be classified as reporting polypharmacy, whereas those with 5 or more conditions but taking fewer than 5 medicines would be classified as not reporting polypharmacy.

We created 2 other proxies of polypharmacy: a cognitive marker (perceived overmedication), and a behavioral marker (cut-down attempt). The cognitive proxy asked 6 questions to assess respondents' anxiety regarding 1) short-, medium-, and long-term effects of their current HIV medicines, including long-term side effects; 2) prospect of having to take increasingly more medicines; 3) potential interactions among medications; 4) potential effect on body

\footnotetext{
The opinions expressed by authors contributing to this journal do not necessarily reflect the opinions of the U.S. Department of Health and Human Services, the Public Health Service, the Centers for Disease Control and Prevention, or the authors' affiliated institutions.
} 
or body shape; 5) potential effect on overall health and well-being; and 6) unknown long-term effects. People were classified as having a perception of overmedication if they affirmed on at least 5 of these questions that they were worried about their intake of medications.

The behavioral proxy (cut-down attempt) was based on the premise that skipping or completely switching medication for the sole purpose of reducing intake of medicines could indicate a person's real or perceived awareness that their medicine intake was high. People were classified as having made a cut-down attempt if they reported skipping their HIV medicines in the past 30 days because they were concerned about medication side effects or if they completely switched regimens to reduce the number of medicines taken.

Self-rated overall health and its composite domains. Participants were asked "How would you describe your [physical/mental/sexual/overall] health over the past 4 weeks?" Response options were the same for physical, mental, sexual, and overall health: very poor, poor, neither good nor poor, good, or very good. Self-ratings of good or very good were classified as optimal health on that domain; all other responses were classified as suboptimal.

Treatment concerns, satisfaction, and aspirations. PLHIV were classified as being recent initiates, treatment experienced, or very treatment experienced. Recent initiates were PLHIV who had been diagnosed within the past 2 years and were on their first regimen. Very treatment experienced were people who switched ART 4 or more times and stopped the penultimate regimen after less than 1 year because of issues with frequency or severity of side effects, noneffectiveness, or resistance. PLHIV not meeting the definition of very treatment experienced or recent initiates were classified as treatment experienced. The survey further assessed participants' awareness of the number of HIV medicines contained in single pills or medications.

"Treatment satisfaction" and "met treatment needs" were defined with affirmative responses to the following questions: "Overall, how satisfied are you with your current HIV medication?" "When it comes to the management of your HIV treatment, do you feel your main HIV care provider meets your personal needs and takes into account the things that are most important to you?" A pessimistic outlook was an affirmative response to at least one of the following: "HIV will reduce my life span," or "Because of my HIV, I do not plan for my old age."

The survey further asked participants about what they prioritized the most when they started ART and what their current priorities were. A new treatment concern was an issue that was not deemed important by the respondent at ART initiation but was currently considered a treatment priority.

Self-reported virologic status. Self-reported virologic control was defined as a response of "undetectable," "suppressed versus detectable," "unsuppressed," "I don't know," or "prefer not to say" to the question "What is your most recent viral load?"

Demographic characteristics. Demographic characteristics were age, gender, sexual orientation, geographic region, urbanicity, race, employment status, year of diagnosis, disease duration, and non-HIV comorbidities.

\section{Statistical analyses}

Descriptive and multivariable analyses were performed to measure the relationships between polypharmacy and measures of overall well-being; subgroup differences were tested with $\chi^{2}$ tests. Multivariable logistic regression analyses adjusted for age, duration of disease, geographic region, comorbidities, urbanicity, education, and sexual orientation. We performed stratified analyses among PLHIV reporting virologic control $(\mathrm{n}=1,536)$ and those not reporting virologic control $(\mathrm{n}=576)$. Significance was set at $P$ $<.05$. All analyses were performed with R Version 3.1.1 (The R Foundation).

\section{Results}

A total of 2,112 people completed our survey (Table 1). Overall, $70.4 \%$ were male, $61.4 \%$ were white, $45.1 \%$ were men who have sex with men, $30.7 \%$ were aged 50 or older, and $23.1 \%$ were diagnosed with HIV in the past 2 years. Geographically, $45.6 \%$ of the sample were from the European Union, 27.6\% were from North America, and $26.8 \%$ were from other parts of the world. The percentage reporting optimal health was as follows by the health domain: physical, 58.1\%; mental, 56.1\%; sexual, 46.8\%; and overall, $55.8 \%$; approximately $58.9 \%$ had less than 1 non-HIV comorbidity. The most common non-HIV conditions PLHIV reported ever being diagnosed with were mental health disorders, including anxiety and depression (20.6\%); hypertension (17.3\%); hypercholesterolemia (16.9\%); insomnia or other sleep disorders (15.6\%); gastrointestinal diseases, including ulcers, reflux, and Crohn's disease $(12.5 \%)$; anemia $(11.5 \%)$; liver disease $(10.8 \%)$; arthritis $(9.4 \%)$; and lung/respiratory diseases $(9.1 \%)$.

Of all participants, $82.0 \%$ reported taking at least one non-HIV pill per day or taking medication currently for at least one nonHIV condition, in addition to their ART. The mean number of pills (HIV and non-HIV combined) per day reported was 4.25 (standard deviation [SD], 2.28). By polypharmacy status, average pill count per day was 6.48 (95\% confidence interval [CI], 6.39-6.57) among people with a report of polypharmacy and 2.63 (95\% CI,

The opinions expressed by authors contributing to this journal do not necessarily reflect the opinions of the U.S. Department of Health and Human Services, the Public Health Service, the Centers for Disease Control and Prevention, or the authors' affiliated institutions. 
2.57-2.69) among those without. Overall prevalence of polypharmacy was $42.1 \%$, and this was highest among the following subgroups: men who have sex with women $(50.5 \%, 211$ of 418$)$ compared with men who have sex with men $(38.9 \%, 369$ of 949$)$ and women $(42.1 \%, 239$ of 568$)(P<.001)$; people aged 50 or older $(54.6 \%, 352$ of 645$)$ compared with those younger than 50 $(36.5 \%, 532$ of 1,457$)(P<.001)$; people diagnosed with HIV before $2010(50.3 \%)$ compared with those diagnosed between 2017 and $2019(33.5 \%, 163$ of 487) or between 2010 and $2016(38.9 \%$, 312 of 802$)(P<.001)$; people living in North America $(52.2 \%$, 304 of 582) compared with those living in the European Union $(33.6 \%, 323$ of 960$)$ or other regions $(45.9 \%, 257$ of 560$)(P<$ $.001)$; people residing in nonmetropolitan areas $(45.2 \%, 424$ of 938) compared with metropolitan areas $(39.5 \%, 460$ of 1,164$)(P=$ $.009)$; and people unemployed or not in the work force $(48.1 \%$, 409 of 850) compared with those employed $(37.9 \%, 475$ of 1,252) $(P<.001)$ (Table 2$)$. Furthermore, prevalence of polypharmacy was $26.8 \%, 36.8 \%$, and $62.8 \%$ among those with 0,1 , or 2 or more non-HIV comorbidities, respectively $(P<.001)$. Results from the 2 proxy definitions for polypharmacy yielded results very similar to those obtained with the more objective count of medications; prevalence was $45.7 \%$ with the cognitive proxy (perceived overmedication) and $43.7 \%$ with the behavioral proxy (cut-down attempt).

Polypharmacy and its association with measures of overall wellbeing. PLHIV reporting polypharmacy had worse measures of overall well-being than those not reporting polypharmacy (Table 3). Prevalence estimates were as follows for those reporting compared with those not reporting polypharmacy, respectively: optimal overall health $(46.6 \%$ vs $62.6 \%, P<.001)$, optimal mental health $(46.9 \%$ vs $62.9 \%, P<.001)$, optimal sexual health $(36.2 \%$ vs $54.5 \%, P<.001)$, and optimal physical health $(44.7 \%$ vs $68.1 \%, P<.001)$. PLHIV reporting polypharmacy also had lower probability of reporting treatment satisfaction $(65.2 \%$ vs $73.1 \%, P$ $<.001)$, positive outlook ( $42.5 \%$ vs $49.8 \%, P=.001)$, and virologic control $(69.7 \%$ vs $75.0 \%, P=.007)$. Consistent results were seen when analyses were stratified by self-reported virologic status (Table 3) (Figure 1).

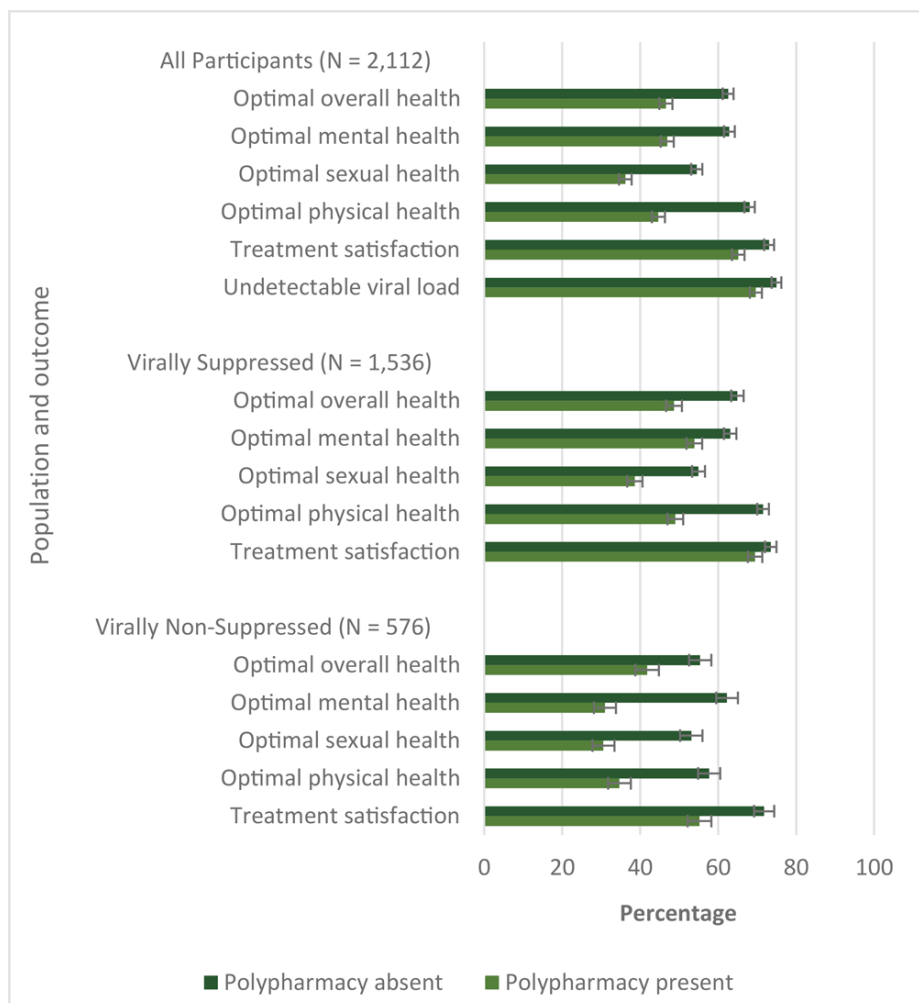

Figure 1. Comparison of prevalence of subjective measures of overall wellbeing by polypharmacy status, people from 24 countries who were living with HIV ( $=2,112)$, Positive Perspectives survey. Polypharmacy was defined as taking 5 or more pills per day for HIV or non-HIV conditions, or taking medicines currently for 5 or more conditions, including HIV. All differences between people with a report of polypharmacy compared with those not reporting polypharmacy were significant at $P<.05$. Brackets indicate standard errors.

After adjusting for potential confounders, including presence of comorbidities, people reporting polypharmacy had significantly worse overall health outcomes and lower odds of reporting virologic control and treatment satisfaction than those who did not. Those reporting polypharmacy compared with those not reporting it in the overall population had lower odds of self-rated optimal overall health (AOR $=0.64 ; 95 \% \mathrm{CI}, 0.53-0.78)$, optimal mental health (AOR $=0.58 ; 95 \% \mathrm{CI}, 0.48-0.71)$, optimal sexual health $(\mathrm{AOR}=0.63 ; 95 \% \mathrm{CI}, 0.52-0.77)$, and optimal physical health $($ AOR $=0.49 ; 95 \%$ CI, 0.41-0.60) $($ Table 3$)$. Analyses of other measures of overall well-being revealed consistent results. People reporting polypharmacy had significantly lower odds, independent of presence of comorbidities, of treatment satisfaction (AOR $=$ $0.73 ; 95 \%$ CI, 0.59-0.91) and self-reported virologic control (AOR $=0.54 ; 95 \% \mathrm{CI}, 0.42-0.70$ ). Stratified analyses on self-reported virologic control status showed that regardless of virologic control, people taking more medicines had less favorable health

\footnotetext{
The opinions expressed by authors contributing to this journal do not necessarily reflect the opinions of the U.S. Department of Health and Human Services, the Public Health Service, the Centers for Disease Control and Prevention, or the authors' affiliated institutions.
} 
outcomes and treatment satisfaction (Figure 1). The association between polypharmacy and measures of overall well-being was, however, stronger among those not reporting than reporting virologic control. For example, polypharmacy reduced the odds of reporting optimal mental health by $25 \%(\mathrm{AOR}=0.75 ; 95 \% \mathrm{CI}$, 0.59-0.95) among those reporting virologic control, but by $63 \%$ among those reporting virologic failure $(\mathrm{AOR}=0.37 ; 95 \% \mathrm{CI}$, $0.25-0.54$ ) (Table 3).

Polypharmacy and its associations with new concerns toward medications. Among people who were 2 or more years post HIV/ AIDS diagnosis $(n=1,624)$, a comparison of treatment priorities at time of initiating ART versus priorities at the time of our survey revealed that the 2 concerns with the largest absolute increase in perceived importance were minimizing the long-term impact of HIV treatment (16.1 percentage points difference) and reducing the number of medications in ART (15.0 percentage points difference) (Figure 2). Prevalence of new ART-related concerns among people who were 2 or more years post HIV/AIDS diagnosis and who did not report those concerns at ART initiation was as follows: risk of side effects $(46.6 \%, 337$ of 724$)$; risk of long-term effects, including potential damage to organs such as kidneys or bones $(45.5 \%, 411$ of 904$)$; risk of transmission to a partner (40.4\%, 347 of 860$)$; perceived need to reduce number of medications in ART $(35.7 \%, 378$ of 1,059); risk of drug-drug interactions $(29.4 \%, 323$ of 1,100); management of HIV-related illnesses (29.4\%, 221 of 751$)$; flexibility with meals or time taken $(29.0 \%$, 300 of 1,035); availability/accessibility (19.5\%, 226 of 1,162); cost (13.9\%, 172 of 1,239); and childbearing (10.2\%, 143 of 1,401). Polypharmacy and current experience of side effects were significantly associated with new concerns regarding drug-drug interactions, and side effects (Table 4). Within adjusted analyses, PLHIV reporting polypharmacy had significantly increased odds of having new concerns about the risk of drug-drug interactions $(\mathrm{AOR}=1.32 ; 95 \% \mathrm{CI}, 1.02-1.71)$, and of side effects $(\mathrm{AOR}=$ $1.31,95 \% \mathrm{CI}, 1.02-1.68)$. PLHIV who perceived themselves as overmedicated also had higher odds of reporting new concerns about the following: number of medications in their ART and the need to keep them at a minimum $(\mathrm{AOR}=1.54 ; 95 \% \mathrm{CI}$, $1.22-1.95)$, risk of drug-drug interactions $(\mathrm{AOR}=1.38 ; 95 \% \mathrm{CI}$, $1.08-1.77)$, flexibility of dosing (AOR $=1.41 ; 95 \% \mathrm{CI}$, $1.10-1.82)$, and availability of ART (AOR $=1.39 ; 95 \% \mathrm{CI}$, 1.05-1.85). PLHIV who were experiencing side effects from their ART at the time of our survey had higher odds of reporting new concerns regarding risk of side effects $(\mathrm{AOR}=1.53 ; 95 \% \mathrm{CI}$, 1.20-1.96) and concerns about viral suppression and disease transmission to a partner $(\mathrm{AOR}=1.29 ; 95 \% \mathrm{CI}, 1.01-1.65)$.

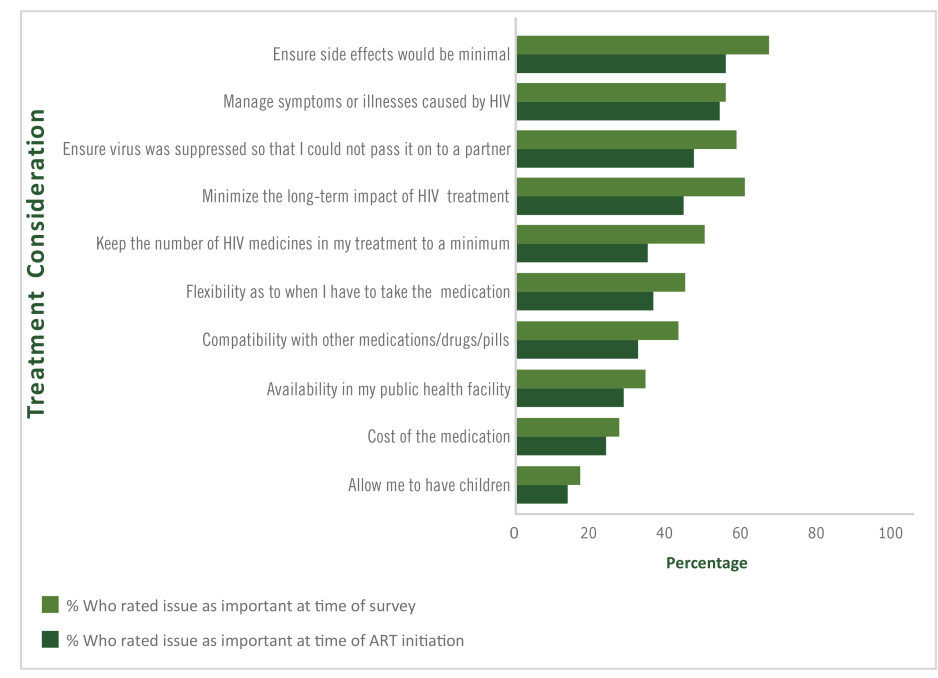

Figure 2. Perceived treatment priorities at initiation of antiretroviral therapy and at the time of the Positive Perspectives survey among treatment experienced people from 24 countries who had been living with HIV for 2 years or longer $(n=1,624), 2019$.

Determinants of openness to taking ART with fewer medicines. Most (75.1\%) PLHIV were aware of the number of medicines their ART medications contained (Table 2). Of all participants, $73.1 \%$ were open to switching to an ART that contained fewer medications as long as their viral load was suppressed. Willingness to switch was highest among men who have sex with men $(77.9 \%, 742$ of 953$)$ vs men who have sex with women $(63.8 \%$, 268 of 420) and women who have sex with men $(63.8 \%, 263$ of 369) $(P<.001)$; people aged 50 or older $(79.9 \%, 518$ of 648$)$ compared with those younger than $50(70.1 \%, 1,026$ of 1,464) $(P<$ $.001)$; those living with HIV the longest (ie, diagnosed pre-2010 [76.4\%] compared with those diagnosed between 2010 and 2016 $[70.1 \%, 564$ of 805$]$ or 2017 and 2019 [72.5\%, 354 of 488]) $(P=$ $.014)$, and those living in metropolitan areas $(76.3 \%, 893$ of 1,170$)$ compared with nonmetropolitan areas $(69.1 \%, 651$ of 942$)(P<$ $.001)$. Furthermore, willingness to switch increased with increasing number of comorbidities and was $68.8 \%, 73.3 \%$, and $77.9 \%$ among those reporting 0,1 , or 2 or more comorbidities, respectively $(P<.001)$. Interest in taking fewer medicines increased with increasing number of concomitant medications; 70.3\% (850 of $1,209)$ of people on ART only and no other medication indicated willingness to switch to ART with fewer medicines. This percentage increased to 77.8 (326 of 419) among those with 1 medication in addition to ART and to $76.0 \%$ (368 of 484) among those with 2 or more other medications.

Overall, 73.4\% $(n=1,550)$ of study participants had ever switched ART since starting treatment. Top reasons for switching among

The opinions expressed by authors contributing to this journal do not necessarily reflect the opinions of the U.S. Department of Health and Human Services, the Public Health Service, the Centers for Disease Control and Prevention, or the authors' affiliated institutions. 
those who had ever switched were to reduce the severity or frequency of side effects $(45.3 \%)$ and to reduce the number of pills $(35.0 \%)$ or number of medicines $(26.8 \%)$ taken. Other specified reasons were because of ineffectiveness or resistance $(24.4 \%)$, drug-drug interactions (18.6\%), or cost (14.8\%). Of all participants, $32.0 \%$ reported skipping their ART on at least one occasion in the past 30 days out of concerns for immediate or longterm side effects.

In total, $44.3 \%$ of participants experienced side effects from their ART, and $41.8 \%$ of all participants felt HIV had a negative effect on their life. Specific ART-related concerns among the overall sample included risks of long-term effects of HIV medicines $(66.6 \%)$ and the risk for drug-drug interactions (48.5\%) (Table 2).

\section{Discussion}

Polypharmacy was strongly associated with poorer health-related quality of life outcomes among PLHIV, independent of the presence of existing comorbidities. These findings were consistent both among those reporting and not reporting virologic suppression, although prevalence estimates of poor health outcomes were significantly higher among the latter. The finding of significant associations even among those reporting viral suppression supports the idea espoused in the fourth 90 of the UNAID's 90-90-90 framework that quality of life is not about just virologic control. In our study, one of the most common reasons PLHIV switched ART in the past was to reduce the number of medicines or pills they had to take, and 2 in 3 PLHIV were willing to switch to an ART with fewer medications as long as their viral load was suppressed. Concurrent use of multiple medications may considerably increase risk of drug-drug interactions, especially among people with concomitant medications (22-24), and this concern was well reflected in our study. Recent studies have established that the number of drug-drug interactions increases with the number of medications (22-24). Most non-HIV conditions reported by PLHIV in our study were chronic conditions largely found in the general population, such as mental health conditions, hypertension, and hypercholesterolemia, which may require long-term management with medications. But even besides concerns regarding the risk of drug-drug interactions, increased use of medicines was associated with poor treatment satisfaction among PLHIV in our study.

Our findings emphasize that treatment needs are constantly evolving; continuous communication between patients and providers is therefore critical. For example, PLHIV experiencing side effects from their ART at the time of the study had significantly higher odds of reporting worries about the risk of side effects as a new concern relative to when they started ART. The most common new concerns among PLHIV were the risks of side effects, long-term effects, disease transmission to a partner, and the number of medicines in ART. Number of medicines in ART, along with concerns about long-term effects of HIV medicines, had the largest absolute increase as important treatment considerations at the time of our survey relative to time of ART initiation among treatment experienced PLHIV. These evolutions in patient preferences with age or onset of other comorbidities highlight the need to constantly re-evaluate current and future treatment needs of PLHIV on the basis of patient-specific risks of comorbidities, co-existing conditions, concomitant medications, and patient concerns about treatment. A proactive treatment plan that considers the totality of a patient's current treatments and risks can result in a more holistic care that optimizes patient well-being.

Health-related quality of life outcomes are harder to quantify as measures of success, and most clinicians have limited power over upstream factors that affect overall well-being, such as socio-economic status. However, our study demonstrates the role of drug treatment on well-being within the context of increased medicines and how providers can positively affect care. By assessing patients holistically, considering their treatment needs and concerns, and streamlining treatments where appropriate, clinicians may contribute to improving patients' health-related quality of life. Alleviating anxiety through regular and continued communication and education may also reduce the worries and concerns reported in this study.

Our study suggests that patients were willing to switch to treatments with fewer medications, despite more than 2 in 3 reporting treatment satisfaction. Regardless of a patient's current viral load, constant review and assessment of treatment plans may be beneficial because patient needs and understanding of their medication evolve over time. Health care providers should be encouraged to simplify treatments where possible, discuss patients' treatment concerns, and share decision making with them, as well as provide them with information on newer treatments that may be beneficial to them.

HIV specialist clinicians can work holistically as part of a multidisciplinary team to address the various treatment-related concerns, worries, and anxieties identified in our study, especially among patients at greatest risk of receiving fragmented care, including older people, those with multiple disorders, those living in poverty, the uninsured, and patients in rural areas. The metrics for evaluating successful disease management, should focus not only on clinical endpoints, but also on patient-oriented outcomes and treatment satisfaction to ensure overall wellbeing. Enhanced and sustained efforts in this regard will ensure progress toward the $\mathrm{Na}$ tional HIV/AIDS strategy, a 5-year plan developed by the US department of Health and Human Services in response to the HIV epidemic (19).

\footnotetext{
The opinions expressed by authors contributing to this journal do not necessarily reflect the opinions of the U.S. Department of Health and Human Services, the Public Health Service, the Centers for Disease Control and Prevention, or the authors' affiliated institutions.
} 
A strength of our study is its use of a standardized protocol in 24 countries. To the best of our knowledge, this is one of the largest studies of PLHIV to assess patient-centered outcomes, including aspirations and attitudes toward treatment. Nonetheless, our study had limitations. First, the cross-sectional design limited any causal inferences. Second, self-reported measures such as viral load may have resulted in misclassification. For example, we classified both people reporting their viral load as detectable or unsuppressed and those who reported they did not know or who refused to answer as virally failing, which may result in misclassification of those with indeterminate status; however, the extent of bias is likely small because of the small percentage this group comprised. Third, the sample may be biased because of nonprobabilistic sampling and the use of a web-based questionnaire. Finally, only a limited number of countries were included. For example, although Africa bears the largest HIV burden in the world, no country in sub-Saharan Africa was included in our analyses.

Approximately 2 in 5 PLHIV surveyed reported polypharmacy, which was significantly associated with poorer health-related quality of life outcomes. A high number of study participants also reported being worried about taking more medicines as they grew older; many were open to switching to ART with fewer medicines, especially people with kidney and bone disorders. Clinicians should consider addressing patient concerns and worries along with treatment. Doing so may help improve health-related quality of life among PLHIV and accelerate progress toward meeting UNAID's fourth 90 .

\section{Acknowledgments}

Financial support for primary data collection came from ViiV Healthcare. Fielding of the survey was conducted by Ipsos Healthcare. Data analyses and editorial services were performed by Zatum LLC and reviewed by Constantine Vardavas, MD, MPH, $\mathrm{PhD}$. We especially acknowledge participants and patient advocacy groups that supported enrollment. No copyrighted materials were included in this article.

\section{Author Information}

Corresponding Author: Chinyere Okoli MSc, ViiV Healthcare, 980 Great West Rd, Brentford Middlesex, United Kingdom TW8 9GS. Telephone: 011-44-78-80-040 307. Email: Chinyere.x.okoli@viivhealthcare.com.

Author Affiliations: ${ }^{1}$ ViiV Healthcare, Brentford Middlesex, United Kingdom. ${ }^{2}$ ViiV Healthcare, Research Triangle Park, North Carolina. ${ }^{3}$ AIDS Center Foundation, Moscow, Russia. ${ }^{4}$ UK $\mathrm{CAB}$ and Positively UK, London, United Kingdom.

\section{References}

1. Shiels MS, Chernyavskiy P, Anderson WF, Best AF, Haozous EA, Hartge P, et al. Trends in premature mortality in the USA by sex, race, and ethnicity from 1999 to 2014: an analysis of death certificate data. Lancet 2017;389(10073):1043-54.

2. Lesko CR, Cole SR, Hall HI, Westreich D, Miller WC, Eron JJ, et al.; CNICS Investigators. The effect of antiretroviral therapy on all-cause mortality, generalized to persons diagnosed with HIV in the USA, 2009-11. Int J Epidemiol 2016;45(1):140-50.

3. Trickey A, May MT, Vehreschild J-J, Obel N, Gill MJ, Crane HM, et al.; Antiretroviral Therapy Cohort Collaboration. Survival of HIV-positive patients starting antiretroviral therapy between 1996 and 2013: a collaborative analysis of cohort studies. Lancet HIV 2017;4(8):e349-56.

4. Trickey A, May MT, Vehreschild J, Obel N, Gill MJ, Crane H, et al.; Antiretroviral Therapy Cohort Collaboration (ART-CC). Cause-Specific mortality in HIV-positive patients who survived ten years after starting antiretroviral therapy. PLoS One 2016;11(8):e0160460.

5. Maggi P, Santoro CR, Nofri M, Ricci E, De Gennaro N, Bellacosa $\mathrm{C}$, et al. Clusterization of comorbidities and multimorbidities among persons living with HIV: a cross-sectional study. BMC Infect Dis 2019;19(1):555.

6. Rodriguez-Penney AT, Iudicello JE, Riggs PK, Doyle K, Ellis RJ, Letendre SL, et al.; HIV Neurobehavioral Research Program HNRP Group. Comorbidities in persons infected with HIV: increased burden with older age and negative effects on health-related quality of life. AIDS Patient Care STDS 2013; 27(1):5-16.

7. World Health Organization. Constitution. https://www.who.int/ about/who-we-are/constitution. Accessed September 19, 2019.

8. Lazarus JV, Safreed-Harmon K, Barton SE, Costagliola D, Dedes N, Del Amo Valero J, et al. Beyond viral suppression of HIV — the new quality of life frontier. BMC Med 2016; 14(1):94.

9. Degroote S, Vogelaers D, Vandijck DM. What determines health-related quality of life among people living with HIV: an updated review of the literature. Arch Public Health 2014; 72(1):40.

10. Masnoon N, Shakib S, Kalisch-Ellett L, Caughey GE. What is polypharmacy? A systematic review of definitions. BMC Geriatr 2017;17(1):230.

11. Siefried KJ, Mao L, Cysique LA, Rule J, Giles ML, Smith DE, et al.; PAART study investigators. Concomitant medication polypharmacy, interactions and imperfect adherence are common in Australian adults on suppressive antiretroviral therapy. AIDS 2018;32(1):35-48.

The opinions expressed by authors contributing to this journal do not necessarily reflect the opinions of the U.S. Department of Health and Human Services, the Public Health Service, the Centers for Disease Control and Prevention, or the authors' affiliated institutions. 
12. Guaraldi G, Malagoli A, Calcagno A, Mussi C, Celesia BM, Carli F, et al. The increasing burden and complexity of multimorbidity and polypharmacy in geriatric HIV patients: a cross sectional study of people aged 65-74 years and more than 75 years. BMC Geriatr 2018;18(1):99.

13. Justice AC, Gordon KS, Skanderson M, Edelman EJ, Akgün KM, Gibert CL, et al.; VACS Project Team. Nonantiretroviral polypharmacy and adverse health outcomes among HIVinfected and uninfected individuals. AIDS 2018;32(6):739-49.

14. Gimeno-Gracia M, Crusells-Canales MJ, Armesto-Gómez FJ, Compaired-Turlán V, Rabanaque-Hernández MJ. Polypharmacy in older adults with human immunodeficiency virus infection compared with the general population. Clin Interv Aging 2016;11(11):1149-57.

15. Greene M, Steinman MA, McNicholl IR, Valcour V. Polypharmacy, drug-drug interactions, and potentially inappropriate medications in older adults with human immunodeficiency virus infection. J Am Geriatr Soc 2014; 62(3):447-53.

16. Edelman EJ, Gordon KS, Glover J, McNicholl IR, Fiellin DA, Justice AC. The next therapeutic challenge in HIV: polypharmacy. Drugs Aging 2013;30(8):613-28.

17. Engler K, Lessard D, Lebouché B. A review of HIV-specific patient-reported outcome measures. Patient 2017; 10(2):187-202.

18. Bristowe K, Clift P, James R, Josh J, Platt M, Whetham J, et al. Towards person-centered care for people living with HIV: what core outcomes matter, and how might we assess them? A cross-national multi-centre qualitative study with key stakeholders. HIV Med 2019;20(8):542-54.

19. HIV.gov. National HIV/AIDS strategy. https://www.hiv.gov/ federal-response/national-hiv-aids-strategy/overview. Accessed September 19, 2019.

20. Gleason LJ, Luque AE, Shah K. Polypharmacy in the HIVinfected older adult population. Clin Interv Aging 2013; 8:749-63.

21. US Department of Health and Human Services. AIDS Info. Guidelines for the use of antiretroviral agents in adults and adolescents with HIV. https://aidsinfo.nih.gov/guidelines/html/ 1/adult-and-adolescent-arv/11/what-to-start. Accessed September 19, 2019.

22. Castilho ECD, Reis AMM, Borges TL, Siqueira LDC, Miasso AI. Potential drug-drug interactions and polypharmacy in institutionalized elderly patients in a public hospital in Brazil. J Psychiatr Ment Health Nurs 2018;25(1):3-13.

23. Shetty V, Chowta MN, Chowta K N, Shenoy A, Kamath A, Kamath P. Evaluation of potential drug-drug interactions with medications prescribed to geriatric patients in a tertiary care hospital. J Aging Res 2018;2018:5728957.
24. Holtzman C, Armon C, Tedaldi E, Chmiel JS, Buchacz K, Wood K, et al.; and the HOPS Investigators. Polypharmacy and risk of antiretroviral drug interactions among the aging HIV-infected population. J Gen Intern Med 2013; 28(10):1302-10.

\footnotetext{
The opinions expressed by authors contributing to this journal do not necessarily reflect the opinions of the U.S. Department of Health and Human Services, the Public Health Service, the Centers for Disease Control and Prevention, or the authors' affiliated institutions.
} 


\section{Tables}

Table 1. Sociodemographic and Clinical Characteristics of People Living With HIV (N=2,112) in 24 Countries and Measures of Self-Rated Health, Positive Perspectives Study, $2019^{a}$

\begin{tabular}{|c|c|c|c|c|c|c|}
\hline \multirow[b]{2}{*}{ Variable } & \multicolumn{6}{|c|}{ Subjective Measures of Quality of Life, \% } \\
\hline & No. & $\begin{array}{l}\text { Optimal Overall } \\
\text { Health }^{b}\end{array}$ & $\begin{array}{l}\text { Optimal Mental } \\
\text { Health }^{b}\end{array}$ & $\begin{array}{c}\text { Optimal Sequal } \\
\text { Health }^{b}\end{array}$ & $\begin{array}{l}\text { Optimal Physical } \\
\text { Health }^{\text {b }}\end{array}$ & $\begin{array}{l}\text { Treatment } \\
\text { Satisfaction }\end{array}$ \\
\hline Total & 2,112 & 55.8 & 56.1 & 46.8 & 58.1 & 69.6 \\
\hline \multicolumn{7}{|l|}{ Gender } \\
\hline Male & 1,486 & 58.1 & 56.1 & 46.6 & 60.1 & 72.5 \\
\hline Female & 571 & 50.1 & 54.6 & 46.4 & 51.1 & 62.9 \\
\hline Other & 55 & 54.5 & 70.9 & 58.2 & 78.2 & 60.0 \\
\hline \multicolumn{7}{|l|}{ Sexual orientation } \\
\hline Heterosexual & 804 & 48.5 & 47.1 & 43.2 & 48.4 & 59.0 \\
\hline Homosexual & 1,023 & 61.8 & 61.4 & 48.1 & 65.3 & 77.8 \\
\hline Other & 285 & 55.1 & 62.5 & 52.6 & 60.0 & 70.2 \\
\hline \multicolumn{7}{|l|}{ Gender/sexual orientation } \\
\hline Men who have sex with men & 953 & 62.4 & 61.7 & 48.2 & 66.3 & 78.4 \\
\hline Men who have sex with women & 420 & 50.7 & 43.8 & 44.8 & 48.8 & 60.0 \\
\hline Women who have sex with women & 58 & 45.8 & 50.1 & 41.5 & 47.2 & 57.7 \\
\hline Women who have sex with men & 369 & 51.7 & 56.9 & 43.1 & 48.3 & 69.0 \\
\hline Other/indeterminate & 312 & 55.1 & 62.5 & 52.6 & 60.6 & 69.9 \\
\hline \multicolumn{7}{|l|}{ Age, y } \\
\hline$<50$ & 1,464 & 57.2 & 54.1 & 50.6 & 59.7 & 67.6 \\
\hline$\geq 50$ & 648 & 52.8 & 60.6 & 38.3 & 54.6 & 74.1 \\
\hline \multicolumn{7}{|l|}{ Year of HIV diagnosis } \\
\hline 2017-2019 & 488 & 51.8 & 53.1 & 46.9 & 56.4 & 64.1 \\
\hline 2010-2016 & 805 & 58.4 & 55.7 & 51.6 & 58.6 & 70.3 \\
\hline Before 2010 & 819 & 55.7 & 58.4 & 42.1 & 58.7 & 72.2 \\
\hline \multicolumn{7}{|l|}{ Geographic region } \\
\hline European Union & 964 & 57.5 & 60.3 & 51.2 & 62.8 & 72.1 \\
\hline North America & 583 & 55.6 & 50.1 & 39.5 & 52.5 & 71.2 \\
\hline Other & 565 & 53.3 & 55.2 & 46.9 & 56.1 & 63.7 \\
\hline \multicolumn{7}{|l|}{ Home ownership } \\
\hline Own & 653 & 55.7 & 56.7 & 44.7 & 55.4 & 72.0 \\
\hline Rent & 825 & 57.8 & 57.3 & 47.9 & 61.3 & 70.9 \\
\hline Other & 634 & 53.3 & 53.9 & 47.6 & 56.8 & 65.5 \\
\hline
\end{tabular}

a Participating countries were Argentina, Austria, Australia, Belgium, Brazil, Canada, Chile, China, France, Germany, Ireland, Italy, Japan, Mexico, Netherlands, Poland, Portugal, Russia, South Korea, Spain, Switzerland, Taiwan, United Kingdom, and United States.

${ }^{b}$ Self-rated health as good or very good was classified as optimal; ratings of very poor, poor, or neither good nor poor were classified as suboptimal health.

${ }^{c}$ Recent initiates were people living with HIV (PLHIV) who had been diagnosed within the past 2 years and were on their first regimen. Very treatment experienced were people who switched antiretroviral therapy 4 or more times and stopped the penultimate regimen after less than 1 year because of issues with frequency or severity of side effects, noneffectiveness, or resistance. PLHIV not meeting the definition of very treatment experienced or recent initiates were classified as treatment experienced.

(continued on next page)

The opinions expressed by authors contributing to this journal do not necessarily reflect the opinions of the U.S. Department of Health and Human Services, the Public Health Service, the Centers for Disease Control and Prevention, or the authors' affiliated institutions. 
(continued)

Table 1. Sociodemographic and Clinical Characteristics of People Living With HIV $(\mathrm{N}=2,112)$ in 24 Countries and Measures of Self-Rated Health, Positive Perspectives Study, 2019

\begin{tabular}{|c|c|c|c|c|c|c|}
\hline \multirow[b]{2}{*}{ Variable } & \multicolumn{6}{|c|}{ Subjective Measures of Quality of Life, \% } \\
\hline & No. & $\begin{array}{l}\text { Optimal Overall } \\
\text { Health }^{\mathrm{b}}\end{array}$ & $\begin{array}{l}\text { Optimal Mental } \\
\text { Health }\end{array}$ & $\begin{array}{l}\text { Optimal Sexual } \\
\text { Health }^{\text {b }}\end{array}$ & $\begin{array}{l}\text { Optimal Physical } \\
\text { Health }^{\text {o }}\end{array}$ & $\begin{array}{l}\text { Treatment } \\
\text { Satisfaction }\end{array}$ \\
\hline \multicolumn{7}{|l|}{ Urbanicity } \\
\hline Metropolitan & 1,170 & 57.1 & 59.4 & 48.1 & 61.4 & 73.0 \\
\hline Nonmetropolitan & 942 & 54.2 & 52.0 & 45.2 & 54.1 & 65.4 \\
\hline \multicolumn{7}{|l|}{ Employment status } \\
\hline Employed & 1,258 & 61.1 & 58.5 & 51.2 & 62.2 & 72.6 \\
\hline Unemployed/not in workforce & 854 & 48.0 & 52.6 & 40.4 & 52.1 & 65.2 \\
\hline \multicolumn{7}{|l|}{ Race } \\
\hline Nonwhite & 816 & 51.7 & 54.2 & 44.6 & 57.6 & 63.4 \\
\hline White & 1296 & 58.4 & 57.3 & 48.2 & 58.5 & 73.5 \\
\hline \multicolumn{7}{|l|}{ Comorbidity, no. } \\
\hline None & 879 & 64.6 & 58.9 & 57.1 & 64.8 & 72.0 \\
\hline 1 & 464 & 59.1 & 59.5 & 48.9 & 65.3 & 70.9 \\
\hline$\geq 2$ & 769 & 43.8 & 50.8 & 33.8 & 46.2 & 66.1 \\
\hline \multicolumn{7}{|l|}{ Comorbidity, type } \\
\hline None & 879 & 64.6 & 58.9 & 57.1 & 64.8 & 72.0 \\
\hline Cardio-hematologic only & 177 & 62.1 & 69.5 & 53.7 & 67.8 & 70.1 \\
\hline Bone only & 23 & 52.2 & 69.6 & 47.8 & 52.2 & 56.5 \\
\hline Neurologic only & 151 & 53.6 & 44.4 & 43.0 & 65.6 & 72.2 \\
\hline Gastrointestinal only & 56 & 55.8 & 63.5 & 44.2 & 57.7 & 73.1 \\
\hline Pulmonary only & 23 & 73.9 & 60.9 & 69.6 & 78.3 & 78.3 \\
\hline Cancer only & 15 & 73.3 & 66.7 & 53.3 & 73.3 & 80.0 \\
\hline Endocrine/renal only & 23 & 60.9 & 56.5 & 39.1 & 56.5 & 65.2 \\
\hline Multiple & 765 & 43.8 & 50.8 & 33.8 & 46.2 & 66.1 \\
\hline \multicolumn{7}{|l|}{ Concomitant medications } \\
\hline None & 1,209 & 63.4 & 59.1 & 53.8 & 64.6 & 71.5 \\
\hline 1 & 419 & 55.8 & 58.0 & 47.7 & 60.1 & 67.1 \\
\hline$\geq 2$ & 484 & 37.0 & 46.9 & 28.7 & 40.3 & 66.9 \\
\hline \multicolumn{7}{|c|}{ Antiretroviral therapy, switch history, no. of times } \\
\hline None & 562 & 59.6 & 64.8 & 55.2 & 66.0 & 67.6 \\
\hline 1 & 563 & 60.4 & 51.5 & 50.8 & 60.6 & 69.4 \\
\hline 2 & 390 & 49.7 & 45.6 & 42.8 & 46.4 & 66.7 \\
\hline
\end{tabular}

${ }^{\text {a }}$ Participating countries were Argentina, Austria, Australia, Belgium, Brazil, Canada, Chile, China, France, Germany, Ireland, Italy, Japan, Mexico, Netherlands, Poland, Portugal, Russia, South Korea, Spain, Switzerland, Taiwan, United Kingdom, and United States.

${ }^{b}$ Self-rated health as good or very good was classified as optimal; ratings of very poor, poor, or neither good nor poor were classified as suboptimal health.

${ }^{\mathrm{c}}$ Recent initiates were people living with HIV (PLHIV) who had been diagnosed within the past 2 years and were on their first regimen. Very treatment experienced were people who switched antiretroviral therapy 4 or more times and stopped the penultimate regimen after less than 1 year because of issues with frequency or severity of side effects, noneffectiveness, or resistance. PLHIV not meeting the definition of very treatment experienced or recent initiates were classified as treatment experienced.

The opinions expressed by authors contributing to this journal do not necessarily reflect the opinions of the U.S. Department of Health and Human Services, the Public Health Service, the Centers for Disease Control and Prevention, or the authors' affiliated institutions. 
(continued)

Table 1. Sociodemographic and Clinical Characteristics of People Living With HIV $(\mathrm{N}=2,112)$ in 24 Countries and Measures of Self-Rated Health, Positive Perspectives Study, 2019

\begin{tabular}{|c|c|c|c|c|c|c|}
\hline \multirow[b]{2}{*}{ Variable } & \multicolumn{6}{|c|}{ Subjective Measures of Quality of Life, \% } \\
\hline & No. & $\begin{array}{l}\text { Optimal Overall } \\
\text { Health }^{\mathrm{b}}\end{array}$ & $\begin{array}{l}\text { Optimal Mental } \\
\text { Health }^{b}\end{array}$ & $\begin{array}{l}\text { Optimal Sexual } \\
\text { Health }^{\text {b }}\end{array}$ & $\begin{array}{l}\text { Optimal Physical } \\
\text { Health }\end{array}$ & $\begin{array}{l}\text { Treatment } \\
\text { Satisfaction }\end{array}$ \\
\hline 3 & 235 & 57.4 & 57.0 & 44.3 & 61.3 & 78.7 \\
\hline$\geq 4$ & 362 & 48.3 & 60.5 & 33.7 & 52.8 & 70.2 \\
\hline \multicolumn{7}{|c|}{ Antiretroviral therapy, experience ${ }^{c}$} \\
\hline Recent initiate & 241 & 61.0 & 67.6 & 54.4 & 66 & 69.7 \\
\hline Experienced & 1,790 & 55.4 & 54.2 & 46.1 & 57.3 & 70.0 \\
\hline Very experienced & 81 & 50.6 & 63.0 & 40.7 & 53.1 & 60.5 \\
\hline \multicolumn{7}{|l|}{ Self-reported viral load } \\
\hline Unsuppressed/unknown & 576 & 49.0 & 47.6 & 42.5 & 46.9 & 63.7 \\
\hline Suppressed & 1,536 & 58.4 & 59.3 & 48.4 & 62.4 & 71.8 \\
\hline
\end{tabular}

${ }^{a}$ Participating countries were Argentina, Austria, Australia, Belgium, Brazil, Canada, Chile, China, France, Germany, Ireland, Italy, Japan, Mexico, Netherlands, Poland, Portugal, Russia, South Korea, Spain, Switzerland, Taiwan, United Kingdom, and United States.

${ }^{b}$ Self-rated health as good or very good was classified as optimal; ratings of very poor, poor, or neither good nor poor were classified as suboptimal health.

${ }^{c}$ Recent initiates were people living with HIV (PLHIV) who had been diagnosed within the past 2 years and were on their first regimen. Very treatment experienced were people who switched antiretroviral therapy 4 or more times and stopped the penultimate regimen after less than 1 year because of issues with frequency or severity of side effects, noneffectiveness, or resistance. PLHIV not meeting the definition of very treatment experienced or recent initiates were classified as treatment experienced.

The opinions expressed by authors contributing to this journal do not necessarily reflect the opinions of the U.S. Department of Health and Human Services, the Public Health Service, the Centers for Disease Control and Prevention, or the authors' affiliated institutions. 
Table 2. Polypharmacy and Perceptions of HIV Medications Among People Living With HIV $(\mathrm{N}=2,112)$ in 24 Countries, Positive Perspectives Study, $2019^{a}$

\begin{tabular}{|c|c|c|c|c|c|c|c|}
\hline \multirow[b]{2}{*}{ Variable } & \multicolumn{7}{|c|}{ Polypharmacy and Concerns About Medicines, \% } \\
\hline & No. & Polypharmacy $^{b}$ & $\begin{array}{l}\text { Awareness of } \\
\text { No. of } \\
\text { Medicines in } \\
\text { Their Daily } \\
\text { Regimen }\end{array}$ & $\begin{array}{l}\text { Worry About } \\
\text { More } \\
\text { Medicines }\end{array}$ & $\begin{array}{l}\text { Worry About } \\
\text { Long-Term } \\
\text { Effects } \\
\text { of Medicines }\end{array}$ & $\begin{array}{l}\text { Worry About } \\
\text { Drug-Drug } \\
\text { Interactions }\end{array}$ & $\begin{array}{l}\text { Open to Taking } \\
\text { Fewer HIV } \\
\text { Medicines }\end{array}$ \\
\hline Total & 2,112 & 42.1 & 75.1 & 56.6 & 66.6 & 48.5 & 73.1 \\
\hline \multicolumn{8}{|l|}{ Gender } \\
\hline Male & 1,486 & 42.8 & 77.0 & 55.7 & 66.2 & 46.5 & 73.9 \\
\hline Female & 571 & 42.1 & 72.7 & 58.7 & 67.4 & 52.5 & 71.5 \\
\hline Other & 55 & 20.4 & 49.1 & 60.0 & 69.1 & 60.0 & 69.1 \\
\hline \multicolumn{8}{|l|}{ Sexual orientation } \\
\hline Heterosexual & 804 & 48.3 & 71.0 & 55.3 & 66.2 & 49.1 & 67.5 \\
\hline Homosexual & 1,023 & 38.7 & 79.9 & 56.4 & 67.4 & 45.7 & 76.9 \\
\hline Other & 285 & 36.5 & 69.5 & 60.7 & 64.9 & 56.5 & 75.1 \\
\hline \multicolumn{8}{|l|}{ Gender/sexual orientation } \\
\hline Men who have sex with men & 953 & 38.9 & 80.4 & 56.2 & 68.3 & 45.2 & 77.9 \\
\hline Men who have sex with women & 420 & 50.5 & 68.3 & 53.8 & 61.0 & 47.9 & 63.8 \\
\hline Women who have sex with women & 58 & 47.0 & 74.0 & 56.6 & 71.5 & 49.9 & 71.3 \\
\hline Women who have sex with men & 369 & 37.9 & 77.6 & 58.6 & 55.2 & 51.7 & 63.8 \\
\hline Other/indeterminate & 312 & 35.4 & 68.9 & 60.9 & 65.1 & 57.1 & 75.0 \\
\hline \multicolumn{8}{|l|}{ Age, y } \\
\hline$<50$ & 1,464 & 36.5 & 72.3 & 57.7 & 65.9 & 50.8 & 70.1 \\
\hline$\geq 50$ & 648 & 54.6 & 81.3 & 54.2 & 68.1 & 43.4 & 79.9 \\
\hline \multicolumn{8}{|l|}{ Year of HIV diagnosis } \\
\hline 2017-2019 & 488 & 33.5 & 75.4 & 58.8 & 63.7 & 53.3 & 72.5 \\
\hline 2010-2016 & 805 & 38.9 & 73.4 & 56.3 & 64.1 & 49.9 & 70.1 \\
\hline Before 2010 & 819 & 50.3 & 76.6 & 55.6 & 70.7 & 44.2 & 76.4 \\
\hline \multicolumn{8}{|l|}{ Geographic region } \\
\hline European Union & 964 & 33.6 & 70.5 & 55.5 & 65.5 & 43.8 & 73.9 \\
\hline North America & 583 & 52.2 & 80.4 & 55.6 & 62.8 & 49.1 & 69.8 \\
\hline Other & 565 & 45.9 & 77.3 & 59.5 & 72.4 & 55.9 & 75.2 \\
\hline \multicolumn{8}{|l|}{ Home ownership } \\
\hline Own & 653 & 50.5 & 81.8 & 55.1 & 66.9 & 47.2 & 75.7 \\
\hline Rent & 825 & 38.9 & 73.8 & 55.6 & 66.1 & 47.6 & 75.8 \\
\hline Other & 634 & 37.4 & 69.9 & 59.3 & 66.9 & 50.9 & 67.0 \\
\hline \multicolumn{8}{|l|}{ Urbanicity } \\
\hline Metropolitan & 1,170 & 39.5 & 73.8 & 59.0 & 71.2 & 49.4 & 76.3 \\
\hline Nonmetropolitan & 942 & 45.2 & 76.6 & 53.6 & 60.8 & 47.3 & 69.1 \\
\hline Employment status & & & & & & & \\
\hline
\end{tabular}

${ }^{a}$ Participating country were Argentina, Austria, Australia, Belgium, Brazil, Canada, Chile, China, France, Germany, Ireland, Italy, Japan, Mexico, Netherlands, Poland, Portugal, Russia, South Korea, Spain, Switzerland, Taiwan, United Kingdom, and United States.

${ }^{\mathrm{b}}$ Polypharmacy was defined as taking 5 or more pills per day for HIV or non-HIV conditions, or taking medicines for 5 or more conditions, including HIV.

(continued on next page)

The opinions expressed by authors contributing to this journal do not necessarily reflect the opinions of the U.S. Department of Health and Human Services, the Public Health Service, the Centers for Disease Control and Prevention, or the authors' affiliated institutions. 
(continued)

Table 2. Polypharmacy and Perceptions of HIV Medications Among People Living With HIV (N=2,112) in 24 Countries, Positive Perspectives Study, $2019^{a}$

\begin{tabular}{|c|c|c|c|c|c|c|c|}
\hline \multirow[b]{2}{*}{ Variable } & \multicolumn{7}{|c|}{ Polypharmacy and Concerns About Medicines, \% } \\
\hline & No. & Polypharmacy ${ }^{\mathrm{b}}$ & $\begin{array}{l}\text { Awareness of } \\
\text { No. of } \\
\text { Medicines in } \\
\text { Their Daily } \\
\text { Regimen }\end{array}$ & $\begin{array}{l}\text { Worry About } \\
\text { More } \\
\text { Medicines }\end{array}$ & $\begin{array}{l}\text { Worry About } \\
\text { Long-Term } \\
\text { Effects } \\
\text { of Medicines }\end{array}$ & $\begin{array}{l}\text { Worry About } \\
\text { Drug-Drug } \\
\text { Interactions }\end{array}$ & $\begin{array}{l}\text { Open to Taking } \\
\text { Fewer HIV } \\
\text { Medicines }\end{array}$ \\
\hline Employed & 1,258 & 37.9 & 76.1 & 54.5 & 63.8 & 47.5 & 74.5 \\
\hline Unemployed/not in workforce & 854 & 48.1 & 73.7 & 59.7 & 70.7 & 50.0 & 71.1 \\
\hline \multicolumn{8}{|l|}{ Race } \\
\hline Nonwhite & 816 & 38.9 & 70.3 & 60.7 & 73.2 & 52.1 & 70.0 \\
\hline White & 1296 & 44.0 & 78.1 & 54.0 & 62.4 & 46.2 & 75.1 \\
\hline \multicolumn{8}{|l|}{ Comorbidity, no. } \\
\hline None & 879 & 26.8 & 70.3 & 52.7 & 58 & 45.1 & 68.8 \\
\hline 1 & 464 & 36.8 & 73.5 & 55.4 & 68.5 & 47.6 & 73.3 \\
\hline$\geq 2$ & 769 & 62.8 & 81.5 & 61.8 & 75.2 & 52.9 & 77.9 \\
\hline \multicolumn{8}{|l|}{ Comorbidity, type } \\
\hline None & 879 & 26.8 & 70.3 & 52.7 & 58.0 & 45.1 & 68.8 \\
\hline Cardio-hematologic only & 177 & 39.2 & 68.4 & 56.5 & 68.9 & 52.0 & 69.5 \\
\hline Bone only & 23 & 34.8 & 91.3 & 34.8 & 65.2 & 34.8 & 82.6 \\
\hline Neurologic only & 151 & 36.4 & 72.8 & 62.9 & 72.8 & 49.7 & 73.5 \\
\hline Gastrointestinal only & 56 & 25.5 & 78.8 & 46.2 & 61.5 & 40.4 & 82.7 \\
\hline Pulmonary only & 23 & 43.5 & 82.6 & 52.2 & 69.6 & 47.8 & 65.2 \\
\hline Cancer only & 15 & 20.0 & 73.3 & 40.0 & 60.0 & 40.0 & 80.0 \\
\hline Endocrine/renal only & 23 & 52.2 & 78.3 & 52.2 & 60.9 & 34.8 & 73.9 \\
\hline Multiple & 765 & 62.8 & 81.5 & 61.8 & 75.2 & 52.9 & 77.9 \\
\hline \multicolumn{8}{|l|}{ Concomitant medications } \\
\hline None & 1,209 & 27.6 & 71.6 & 52.7 & 61.5 & 45.9 & 70.3 \\
\hline 1 & 419 & 42.0 & 75.1 & 58.7 & 70.9 & 48.0 & 77.8 \\
\hline$\geq 2$ & 484 & 78.5 & 84.6 & 64.1 & 74.9 & 54.9 & 76.0 \\
\hline \multicolumn{8}{|c|}{ Switched antiretroviral therapy, no. of times } \\
\hline None & 562 & 19.9 & 62.8 & 55.0 & 62.1 & 46.1 & 67.4 \\
\hline 1 & 563 & 43.7 & 75.7 & 52.4 & 62.7 & 48.7 & 67.0 \\
\hline 2 & 390 & 49.4 & 77.9 & 60.5 & 66.2 & 54.9 & 75.4 \\
\hline 3 & 235 & 44.7 & 79.6 & 57.4 & 71.5 & 45.5 & 80.4 \\
\hline$\geq 4$ & 362 & 64.4 & 87.3 & 60.8 & 76.8 & 47.0 & 84.3 \\
\hline \multicolumn{8}{|c|}{ Antiretroviral therapy, experience with } \\
\hline Recent initiates & 241 & 19.1 & 73.4 & 52.3 & 59.3 & 45.6 & 75.5 \\
\hline Experienced & 1,790 & 44.5 & 74.7 & 56.7 & 66.9 & 48.9 & 72.1 \\
\hline Very experienced & 81 & 56.2 & 88.9 & 66.7 & 80.2 & 46.9 & 88.9 \\
\hline
\end{tabular}

a Participating country were Argentina, Austria, Australia, Belgium, Brazil, Canada, Chile, China, France, Germany, Ireland, Italy, Japan, Mexico, Netherlands, Poland, Portugal, Russia, South Korea, Spain, Switzerland, Taiwan, United Kingdom, and United States.

${ }^{\mathrm{b}}$ Polypharmacy was defined as taking 5 or more pills per day for HIV or non-HIV conditions, or taking medicines for 5 or more conditions, including HIV.

(continued on next page)

The opinions expressed by authors contributing to this journal do not necessarily reflect the opinions of the U.S. Department of Health and Human Services, the Public Health Service, the Centers for Disease Control and Prevention, or the authors' affiliated institutions. 
(continued)

Table 2. Polypharmacy and Perceptions of HIV Medications Among People Living With HIV $(\mathrm{N}=2,112)$ in 24 Countries, Positive Perspectives Study, $2019^{a}$

\begin{tabular}{|c|c|c|c|c|c|c|c|}
\hline \multirow[b]{2}{*}{ Variable } & \multicolumn{7}{|c|}{ Polypharmacy and Concerns About Medicines, \% } \\
\hline & No. & Polypharmacy $^{\text {b }}$ & $\begin{array}{l}\text { Awareness of } \\
\text { No. of } \\
\text { Medicines in } \\
\text { Their Daily } \\
\text { Regimen }\end{array}$ & $\begin{array}{l}\text { Worry About } \\
\text { More } \\
\text { Medicines }\end{array}$ & $\begin{array}{l}\text { Worry About } \\
\text { Long-Term } \\
\text { Effects } \\
\text { of Medicines }\end{array}$ & $\begin{array}{l}\text { Worry About } \\
\text { Drug-Drug } \\
\text { Interactions }\end{array}$ & $\begin{array}{l}\text { Open to Taking } \\
\text { Fewer HIV } \\
\text { Medicines }\end{array}$ \\
\hline \multicolumn{8}{|l|}{ Self-reported viral load } \\
\hline Unsuppressed/unknown & 576 & 46.8 & 76.6 & 54.7 & 56.2 & 51.6 & 71.0 \\
\hline Suppressed & 1,536 & 40.3 & 74.5 & 57.3 & 70.4 & 47.3 & 73.9 \\
\hline
\end{tabular}

a Participating country were Argentina, Austria, Australia, Belgium, Brazil, Canada, Chile, China, France, Germany, Ireland, Italy, Japan, Mexico, Netherlands, Poland, Portugal, Russia, South Korea, Spain, Switzerland, Taiwan, United Kingdom, and United States.

${ }^{b}$ Polypharmacy was defined as taking 5 or more pills per day for HIV or non-HIV conditions, or taking medicines for 5 or more conditions, including HIV. 
Table 3. Prevalence of Study Outcomes Among People Living With HIV in 24 Countries ${ }^{a}$, With or Without a Report of Polypharmacy ${ }^{b}$, Stratified by Self-Reported Virologic Control Status ${ }^{\mathrm{c}}$, Positive Perspectives Study, 2019

\begin{tabular}{|c|c|c|c|c|c|}
\hline \multirow[b]{2}{*}{ Outcome } & \multicolumn{3}{|c|}{ Medication-Count-Based Measure of Polypharmacy } & \multicolumn{2}{|c|}{ Proxy Measure of Polypharmacy } \\
\hline & $\begin{array}{l}\text { Prevalence of Outcome } \\
\text { Among Those Reporting } \\
\text { Polypharmacy } \\
\text { ( } n=884), \%\end{array}$ & $\begin{array}{c}\text { Prevalence of Outcome } \\
\text { Among Those Not } \\
\text { Reporting } \\
\text { Polypharmacy } \\
\text { ( }=1,218), \%\end{array}$ & $\begin{array}{c}\text { Associations With } \\
\text { Polypharmacy and } \\
\text { Outcome, } \\
\text { AOR }(95 \% \mathrm{Cl})^{\mathrm{d}}\end{array}$ & $\begin{array}{c}\text { Associations Between } \\
\text { Perceived } \\
\text { Overmedication and } \\
\text { Outcome, } \\
\text { AOR }(95 \% \mathrm{Cl})^{\mathrm{d}}\end{array}$ & $\begin{array}{c}\text { Associations Between } \\
\text { Cut-Down Attempt and } \\
\text { Outcome, } \\
\text { AOR }(95 \% \mathrm{Cl})^{\mathrm{d}}\end{array}$ \\
\hline \multicolumn{6}{|l|}{ All participants $(\mathrm{N}=2,112)$} \\
\hline Self-rated overall health & 46.6 & 62.6 & $0.64(0.53-0.78)^{e}$ & $0.66(0.55-0.80)^{\mathrm{e}}$ & $0.66(0.54-0.80)^{\epsilon}$ \\
\hline Self-rated mental health & 46.9 & 62.9 & $0.58(0.48-0.71)^{\mathrm{e}}$ & $0.84(0.70-1.01)$ & $0.50(0.42-0.61)^{e}$ \\
\hline Self-rated sexual health & 36.2 & 54.5 & $0.63(0.52-0.77)^{\mathrm{e}}$ & $0.69(0.58-0.83)^{\mathrm{e}}$ & $0.57(0.47-0.69)^{\epsilon}$ \\
\hline Self-rated physical health & 44.7 & 68.1 & $0.49(0.40-0.60)^{\mathrm{e}}$ & $0.95(0.79-1.14)$ & $0.62(0.51-0.76)^{e}$ \\
\hline Treatment satisfaction & 65.2 & 73.1 & $0.73(0.59-0.91)^{\mathrm{e}}$ & $0.72(0.59-0.87)^{\mathrm{e}}$ & $0.57(0.47-0.70)^{e}$ \\
\hline Met treatment needs & 68.7 & 68.5 & $0.96(0.78-1.18)$ & $0.74(0.61-0.89)^{\mathrm{e}}$ & $0.68(0.55-0.83)^{6}$ \\
\hline Positive outlook for longevity & 42.5 & 49.8 & $0.85(0.70-1.04)$ & $0.38(0.31-0.46)^{\mathrm{e}}$ & $0.47(0.39-0.57)^{6}$ \\
\hline \multicolumn{6}{|c|}{ Reporting virologic suppression $(n=1,536)$} \\
\hline Self-rated overall health & 48.7 & 65.0 & $0.65(0.51-0.83)^{\mathrm{e}}$ & $0.61(0.49-0.76)^{\mathrm{e}}$ & $0.74(0.59-0.93)^{\epsilon}$ \\
\hline Self-rated mental health & 53.9 & 63.1 & $0.75(0.59-0.95)^{\mathrm{e}}$ & $0.72(0.58-0.89)^{\mathrm{e}}$ & $0.55(0.44-0.68)^{e}$ \\
\hline Self-rated sexual health & 38.6 & 55.0 & $0.75(0.59-0.95)^{\mathrm{e}}$ & $0.61(0.49-0.75)^{\mathrm{e}}$ & $0.60(0.48-0.75)^{6}$ \\
\hline Self-rated physical health & 49.0 & 71.5 & $0.53(0.42-0.68)^{\mathrm{e}}$ & $0.75(0.60-0.93)^{\mathrm{e}}$ & $0.68(0.54-0.86)^{\epsilon}$ \\
\hline Treatment satisfaction & 69.5 & 73.5 & $0.75(0.58-0.98)^{\mathrm{e}}$ & $0.67(0.53-0.85)^{\mathrm{e}}$ & $0.52(0.41-0.66)^{e}$ \\
\hline Met treatment needs & 72.2 & 68.1 & $1.05(0.81-1.36)$ & $0.65(0.52-0.82)^{\mathrm{e}}$ & $0.74(0.58-0.94)^{e}$ \\
\hline Positive outlook for longevity & 49.5 & 56.1 & $0.93(0.74-1.18)$ & $0.37(0.30-0.45)^{\mathrm{e}}$ & $0.56(0.45-0.70)^{\epsilon}$ \\
\hline \multicolumn{6}{|c|}{ Not reporting virologic suppression $(n=576)$} \\
\hline Self-rated overall health & 41.8 & 55.4 & $0.73(0.50-1.07)$ & $0.75(0.52-1.09)$ & $0.59(0.40-0.87)^{e}$ \\
\hline Self-rated mental health & 31.0 & 62.3 & $0.37(0.25-0.54)^{\mathrm{e}}$ & $1.35(0.93-1.98)$ & $0.48(0.32-0.71)^{e}$ \\
\hline Self-rated sexual health & 30.6 & 53.1 & $0.44(0.29-0.66)^{\mathrm{e}}$ & $0.88(0.60-1.30)$ & $0.54(0.36-0.82)^{6}$ \\
\hline Self-rated physical health & 34.7 & 57.7 & $0.48(0.32-0.70)^{\mathrm{e}}$ & $1.62(1.11-2.36)^{\mathrm{e}}$ & $0.61(0.41-0.90)^{6}$ \\
\hline Treatment satisfaction & 55.2 & 71.8 & $0.63(0.43-0.94)^{\mathrm{e}}$ & $0.92(0.62-1.36)$ & $0.73(0.48-1.11)$ \\
\hline Met treatment needs & 60.4 & 69.5 & $0.70(0.47-1.04)$ & $0.99(0.67-1.45)$ & $0.51(0.34-0.78)^{\epsilon}$ \\
\hline Positive outlook for longevity & 26.5 & 30.8 & $0.94(0.62-1.42)$ & $0.26(0.17-0.41)^{\mathrm{e}}$ & $0.31(0.21-0.48)^{e}$ \\
\hline
\end{tabular}

Abbreviations: AOR, adjusted odds ratio; $\mathrm{Cl}$, confidence interval.

${ }^{a}$ Countries included in study were Argentina, Austria, Australia, Belgium, Brazil, Canada, Chile, China, France, Germany, Ireland, Italy, Japan, Mexico, Netherlands, Poland, Portugal, Russia, South Korea, Spain, Switzerland, Taiwan, United Kingdom, and United States.

${ }^{\mathrm{b}}$ Polypharmacy was defined as taking 5 or more pills per day for HIV or non-HIV conditions or taking medicines currently for 5 or more conditions, including HIV/ AIDS. For the cognitive proxy (perceived overmedication), we used a set of 6 questions that assessed respondents' anxieties regarding short-, medium-, and longterm effects from their current HIV medicines, including worries about long-term side effects, having to take increasingly more medicines, potential interactions with other medications, impact on body and/or body shape, impact on overall health and well-being, and unknown long-term impact. Being worried about at least 5 of these items was subjectively classified as acute awareness on the part of the respondent of the number of medicines they were taking. For the behavioral proxy (cut-down attempt), participants were classified as having taken deliberate efforts to reduce the number/impact of medicines they were taking if they skipped taking their HIV medicines in the past 30 days because they were concerned about short- or long-term side effects of medicines or if they completely switched medicines to reduce the number of medicines taken.

“Self-reported virologic suppression was defined as a response of “undetectable" or "suppressed" versus "detectable," “unsuppressed," “I don't know," or "prefer not to say" to the question, "What is your most recent viral load?"

${ }^{d}$ Adjusted odds ratios for the different outcomes were computed in separate logistic regression models, controlling for age, duration of disease, geographic region, comorbidities, urbanicity, education, and sexual orientation.

${ }^{\mathrm{e}}$ Significant at $P<.05$.

The opinions expressed by authors contributing to this journal do not necessarily reflect the opinions of the U.S. Department of Health and Human Services, the Public Health Service, the Centers for Disease Control and Prevention, or the authors' affiliated institutions. 
Table 4. Experience of Side Effects, Polypharmacy ${ }^{a}$, Perceived Overmedication, and Cut-Down Attempts as Predictors of New Treatment Concerns ${ }^{b}$ Among People Living With HIV for 2 Years or Longer ( $=1,624)$, Positive Perspectives Study, $2019^{\mathrm{c}}$

\begin{tabular}{|c|c|c|c|c|}
\hline New Treatment Concern & $\begin{array}{c}\text { Report of } \\
\text { Experiencing Side } \\
\text { Effects From ART, } \\
\text { AOR }(95 \% \mathrm{Cl})\end{array}$ & $\begin{array}{c}\text { Polypharmacy, AOR } \\
(95 \% \mathrm{Cl})\end{array}$ & $\begin{array}{l}\text { Perceived } \\
\text { Overmedication, AOR } \\
(95 \% \mathrm{Cl})^{\mathrm{d}}\end{array}$ & $\begin{array}{l}\text { Cut-Down Attempts, } \\
\text { AOR }(95 \% \mathrm{Cl})\end{array}$ \\
\hline Keep number of HIV medicines in ART to a minimum & $1.10(0.86-1.39)$ & $1.26(0.99-1.61)$ & $1.54(1.22-1.95)^{\mathrm{e}}$ & $0.92(0.72-1.18)$ \\
\hline Minimize the long-term impact of HIV treatment & $1.06(0.84-1.33)$ & $1.15(0.91-1.45)$ & $1.12(0.89-1.40)$ & $0.82(0.64-1.04)$ \\
\hline Compatibility with other medications & $1.09(0.84-1.40)$ & $1.32(1.02-1.71)^{\mathrm{e}}$ & $1.38(1.08-1.77)$ & $0.84(0.65-1.10)$ \\
\hline Allow me to have children & $1.31(0.92-1.86)$ & $1.03(0.71-1.49)$ & $1.38(0.98-1.96)$ & $1.69(1.16-2.44)^{\mathrm{e}}$ \\
\hline Viral suppression to prevent transmission to partner & $1.29(1.01-1.65)^{\mathrm{e}}$ & $1.27(0.99-1.63)$ & $1.21(0.95-1.54)$ & $0.90(0.70-1.16)$ \\
\hline Flexibility (eg, time of day, with or without food) & $1.08(0.83-1.40)$ & $1.40(1.07-1.83)^{\mathrm{e}}$ & $1.41(1.10-1.82)$ & $0.87(0.67-1.15)$ \\
\hline Minimal side effects & $1.53(1.20-1.96)^{\mathrm{e}}$ & $1.31(1.02-1.68)^{\mathrm{e}}$ & $1.14(0.90-1.46)$ & $0.81(0.62-1.04)$ \\
\hline Availability of ART in my public health facility & $1.14(0.85-1.52)$ & $1.34(0.99-1.79)$ & $1.39(1.05-1.85)$ & $1.18(0.87-1.59)$ \\
\hline Medication cost & $0.91(0.66-1.27)$ & $1.34(0.96-1.86)$ & $1.09(0.79-1.50)$ & $1.24(0.89-1.73)$ \\
\hline Manage HIV symptoms or illnesses & $1.01(0.76-1.36)$ & $1.22(0.90-1.64)$ & $1.17(0.88-1.56)$ & $1.14(0.84-1.54)$ \\
\hline
\end{tabular}

Abbreviations: AOR, adjusted odds ratio; ART, antiretroviral therapy; $\mathrm{Cl}$, confidence interval.

a Polypharmacy was defined as taking 5 or more pills per day for HIV or non-HIV conditions, or currently taking medicines for 5 or more conditions, including HIV.

${ }^{\mathrm{b}} \mathrm{A}$ new treatment concern was one that was not deemed important by the survey respondent at ART initiation but was considered a priority at the time of this study.

${ }^{\mathrm{c}}$ Among treatment experienced people living with HIV. Separate logistic regression models were fitted for the different outcomes, controlling for age, geographic region, urbanicity, education, and sexual orientation.

${ }^{\mathrm{d}}$ To assess perceived overmedication (cognitive proxy), we used a set of 6 questions that assessed respondents' anxieties regarding their current HIV medications: 1) short-, medium-, and long-term effects of including worries about long-term side effects; 2) having to take more and more medications; 3 ) potential interactions with other medications; 4) effect on body and/or body shape; 5) effect on overall health and well-being; 6) unknown long-term effects. Being worried on at least 5 of these issues was subjectively classified as the respondent's acute awareness of the number of medications they were taking. To assess cut-down attempt (behavioral proxy) we classified people as having taken deliberate efforts to reduce the number and effects of their HIV medications if they skipped taking their medications in the past 30 days because they were concerned about short- or long-term side effects or if they completely switched medications to reduce the number taken.

e Significant at $P<.05$.

The opinions expressed by authors contributing to this journal do not necessarily reflect the opinions of the U.S. Department of Health and Human Services, the Public Health Service, the Centers for Disease Control and Prevention, or the authors' affiliated institutions. 